\title{
An industry perspective on building simulations with solar shading
}

\author{
Helle Foldbjerg Rasmussen ${ }^{1, *}$, and Tobias Skov Pedersen ${ }^{1}$ \\ ${ }^{1}$ MicroShade A/S, Gregersensvej 1F, DK-2630 Taastrup, Denmark
}

\begin{abstract}
This case study illustrates the difficulties that designers encounter when trying to simulate building performance taking both daylight, indoor climate and view out into account. An example of a workflow for combined climate-based daylight and indoor climate calculations using two separate software is shown for illustrating the challenges. Furthermore, the study shows how the evaluation of indoor climate, daylight and view out, in accordance with EN 15251, EN 17037 and EN 14501, can be linked together as a basis for comparison of different solar shading technologies for ZEB buildings.
\end{abstract}

\section{Introduction}

To optimize building design for high performance buildings it is necessary to evaluate the complex interaction between daylight availability, indoor climate and view out. Here the daylight openings are the main deciding parameter and second thereafter is the solar shading.

Traditionally both passive and dynamic solar shading has been included in indoor climate simulations, but only passive shadings has been included in daylight simulations, since the daylight evaluation has been based on daylight factor. However, Climate-Based Daylight Modelling (CBDM) is moving into building certification schemes, standards and national building legislation, which is seen in both BREEAM International [1], LEED v4 [2], the new European Standard EN 17037 [3] and the Danish Building regulation from 2018 [4]. They all use different modifications of spatial daylight autonomy as criteria for daylight evaluation. Therefore, it is now possible to include the dynamic shadings in the daylight evaluation. This will make the choice of shading system based on a more realistic and thorough analysis.

The aim of this case study is therefore; to illustrate the difficulties designers encounter in the process with an example of a workflow for combining CBDM and indoor climate simulations including both passive and dynamic shading systems. And to show a method to evaluate both daylight, indoor climate and view out including both passive and dynamic shading systems.

\section{Evaluation of Solar Shading Performance in Buildings}

A detailed description of how solar shadings can be evaluated is given in [5]. The most important parameters for evaluating solar shading performance in buildings are; the ability to control solar heat gain to prevent overheating and daylight availability. The view out has been included as well, as this is one of the most important aspects for building occupants [6] and often overlooked by designers. Below each of the evaluation parameters are described.

\subsection{Thermal indoor climate}

Thermal indoor climate can be evaluated using EN15251 [7]. The recommended criteria for "class II" buildings is max. $5 \%$ of the occupancy hours where the operative temperature is outside the range of $20-24^{\circ} \mathrm{C}$ during the heating season and $23-26^{\circ} \mathrm{C}$ during the cooling season. For normal occupancy hours, Monday-Friday @ 8-17, $5 \%$ correspond to app. 100 hours. Therefore, a threshold of maximum 100 hours above $26^{\circ} \mathrm{C}$ during occupancy hours is used in this study.

\subsection{Daylight}

The daylight availability can be evaluated using the new European standard EN 17037 [3].

The recommended criteria for "minimum-class" buildings is 300 lux for $50 \%$ of the daylight hours in $50 \%$ of the occupied zone.

The daylight hours are defined as the 4380 hours with most diffuse horizontal illuminance according to EN 17037. The occupancy hours are therefore not considered when evaluating the daylight availability.

\subsection{View out}

In this study both the quality of view out and the quantity of view out is evaluated. There is no common agreed method for evaluation [5], however the method used in this study is an attempt to use a generic approach for comparison, where available data are used without considering the exact site (surrounding obstructions or what is in the field of view). 
The quality of view out through an activated solar shading can be evaluated using EN 14501 [8]. In EN 14501 the view out quality is categorized based on the visual normal-diffuse transmittance $\left(\tau_{\mathrm{v}, \mathrm{n} \text {-dif }}\right)$ and the visual normal-normal transmittance $\left(\tau_{\mathrm{v}, \mathrm{n}-\mathrm{n}}\right)$ and falls in 5 categories; 0-Very little, 1 - Little, 2 - Moderate, 3 Good and 4 - Very good.

In case of lamellas $\tau_{\mathrm{v}, \mathrm{n} \text {-dif }}$ and $\tau_{\mathrm{v}, \mathrm{n}-\mathrm{n}}$ should be taken for the actual tilted state of the lamellas.

The quantity of view out is the fraction of occupied hours where dynamic shadings are not activated.

To evaluate both the quality and quantity of view out in one metric it is suggested in the Danish industryguideline for Building Simulations [9] that the fraction of time with blocked view is weighted with the quality of view. The weighting factors are seen in Table 1 .

Table 1. Weighting factors accounting for the quality of view according to [9]

\begin{tabular}{|l|c|c|}
\hline \multicolumn{2}{|l|}{$\begin{array}{l}\text { View out class according to } \\
\text { EN14501 }\end{array}$} & $\begin{array}{c}\text { Weighting } \\
\text { factors }\end{array}$ \\
\hline Very little view & 0 & 1 \\
\hline Little view & 1 & 0,95 \\
\hline Moderate view & 2 & 0,80 \\
\hline Good view & 3 & 0,60 \\
\hline Very good view & 4 & 0,15 \\
\hline
\end{tabular}

As an example, with a shading of view out class 2 (weighting factor 0,8 ), activated $50 \%$ of occupancy hours, the weighted blocked view is $40 \%$, accounting for both quality and quantity of view.

The industry guideline also recommends a limit for acceptable blocking of view out. For a "minimum-class" building 30\% blocking is allowed, for a "standard -class" building $20 \%$ blocking is allowed and for "ambitiousclass" buildings $12 \%$ blocking is allowed. In this study the recommendation for a "standard-class" building will be used.

\subsubsection{Glare influence on view out}

Glare from daylight can substantially affect the quality and quantity of view out. Therefore, an evaluation of view out should also consider the potential risk of glare.

In this study it was chosen to calculate the daylight glare probability (DGP) to estimate the amount of time, where a glare control device (e.g. curtain) is needed. When a glare control device is needed the view out is completely blocked and it is assumed that the glare control is in view-out-category 0 . A DGP-level of 0,4 was used as the trigger value corresponding to "mostly not disturbing" glare. [3]

\section{Case study}

The study uses a simple two-person office with a window to floor ratio of $25 \%$. It is placed in Copenhagen and six different shading solutions are considered; lowenergy glazing, solar control glazing, MicroShade ${ }^{\circledR}$, dynamic integrated lamellas, dynamic external lamellas and a dynamic external screen. In Table 2 the specification for the glazing are shown and in Table 3 the specifications on the dynamic shadings are shown.

Table 2. Specification of glazing

\begin{tabular}{|l|c|c|c|}
\hline \multirow{2}{*}{ Solar shading system } & \multicolumn{3}{|c|}{ Specifications } \\
\cline { 2 - 4 } & $\begin{array}{c}\mathrm{g}_{0}- \\
\text { value }\end{array}$ & $\mathrm{Lt}_{0}$ & $\begin{array}{c}\text { View } \\
\text { out } \\
\text { class }\end{array}$ \\
\hline 3-layer LowE glazing & 0,56 & 0,74 & - \\
\hline $\begin{array}{l}\text { 3-layer solar control } \\
\text { glazing (Cool-Lite } \\
\text { Xtreme 60/28) }\end{array}$ & 0,26 & 0,53 & $4^{2}$ \\
\hline $\begin{array}{l}\text { 3-layer MicroShade } \\
\text { MS-A glazing }\end{array}$ & 0,36 & 0,46 & 4 \\
\hline $\begin{array}{l}\text { 3-layer LowE glazing } \\
\text { with integrated blinds }\end{array}$ & 0,33 & 0,36 & $2^{1}$ \\
\hline $\begin{array}{l}\text { 3-layer LowE glazing } \\
\text { with external screen }\end{array}$ & 0,10 & 0,10 & 3 \\
\hline $\begin{array}{l}\text { 3-layer LowE glazing } \\
\text { with external lamellas }\end{array}$ & 0,30 & 0,39 & $3^{1}$ \\
\hline
\end{tabular}

${ }^{1}$ The view out class is based on a slat angle of $30^{\circ}$. The view out class for the integrated blinds is lower than external lamellas due to a higher $\tau_{\mathrm{v}, \mathrm{n} \text {-dif }}$ for the product.

${ }^{2}$ According to [9] solar control glazing has a view out class 4 with $\mathrm{LT}<0.7$ and $\mathrm{LT} / \mathrm{g}>1.8$.

Table 3. Specification of dynamic shadings

\begin{tabular}{|l|c|c|}
\hline \multirow{2}{*}{$\begin{array}{l}\text { Solar shading } \\
\text { system }\end{array}$} & \multicolumn{2}{|c|}{ Specifications } \\
\cline { 2 - 3 } $\begin{array}{l}\text { Stages } \\
\text { blinds }\end{array}$ & $\begin{array}{c}\text { Retracted/ } \\
30^{\circ} \text { slat angle }\end{array}$ & $100 \mathrm{~W} / \mathrm{m}^{2}$ \\
\hline External screen & Open $/$ closed & $250 \mathrm{~W} / \mathrm{m}^{2}$ \\
\hline $\begin{array}{l}\text { External } \\
\text { lamellas }\end{array}$ & $\begin{array}{c}\text { Retracted/ } \\
30^{\circ} \text { slat angle }\end{array}$ & $250 \mathrm{~W} / \mathrm{m}^{2}$ \\
\hline
\end{tabular}

The control of integrated blinds has a lower threshold than the external shading systems since it is less effective.

The simple two-person office was used to calculate each of the shading systems at a south, east and west oriented facade - a total of 18 scenarios. The same assumptions for internal heat load, HVAC system, reflectance of surfaces etc. was used for all scenarios to be able to compare the effect of the shading systems. The air change rate was adjusted for each orientation to reach temperatures within maximum of 100 hours/year; however, it was kept the same between the different solar shading systems. Furthermore, an extra set of 
scenarios was calculated for the dynamic shading systems to see the effect of the control strategy.

\section{Modelling glazing and solar shading}

The modelling of glazing and solar shading systems highly depends on the chosen simulation program.

In more advanced energy and indoor climate simulation software, modelling standard shading systems is straight forward as the software packages already have a set of pre-defined generic shading systems. The more simpler software packages can however, be very limited and might only include a shading factor option.

Software packages for climate-based daylight modelling are usually based on Radiance [10], which is the industry-standard for daylight simulations. Therefore, the shading system description should be designed to be used in Radiance for CBDM. Depending on the shading system they can be modelled with a geometric model, BSDF (Bi-Directional Scattering Distribution Function) file, Radiance "glass" material etc. The BSDF format is the only modelling method, which potentially can be used for both indoor climate and CBDM. However, the format is quite new and can only be used in a very limited number of indoor climate simulation software. Therefore, it was chosen not to use BSDF files in this case study. In [11] an example of how to use BSDF file for both indoor climate and CBDM is shown.

Since the CBDM and indoor climate modelling is performed with two different calculation engines usually the same description of the shading and glazing cannot be used and shared between the two. This forces designers to use different models of optical performance to model the same shading systems. This is especially true for dynamic shading systems since the control possibilities in the two calculation engines is often based on different approaches; e.g. solar irradiation on the facade in indoor climate simulations and illuminance level inside the room in daylight simulation software.

In this study the CBDM was carried out in DIVA for Rhino [12], while the indoor climate simulations were performed in IDA ICE [13].

\subsection{Indoor climate modelling in IDA ICE}

IDA ICE was chosen as the tool for energy and indoor climate simulations since it has a very comprehensive database of generic and specific solar shading products including MicroShade ${ }^{\circledR}$. The shading systems used in the study was therefore chosen from this database.

IDA ICE uses spectral glass data and all glazing were therefore modelled spectrally. Also angle dependency of coated glass is taken into account. It was not possible to use spectral data in DIVA, so here the description varies between the two pieces of software.

IDA ICE uses ISO15099 [14] to model solar shadings and have included both interstitial and external shadings making it possible to place MicroShade ${ }^{\circledR}$ inside the glazing where it is actually placed for high precision. Similarly, it was possible to include integrated blinds.

\subsection{CBDM in DIVA for Rhino}

DIVA for Rhino was chosen as the tool for climatebased daylight simulation as it has an "easy to use" interface and hence didn't take too much time to learn compared to Radiance.

The modelling of each of the shading systems in DIVA were based on the description from IDA ICE were possible. The modelling of each shading systems is described below.

\subsubsection{Modelling LowE and solar control glazing}

The LowE and solar control glazing was modelled with the perpendicular light transmittance, which was calculated in IDA ICE. It was not possible to use spectral glass data in DIVA. In DIVA the angle dependency of the glazing is modelled equally for all Radiance "glass" materials, that is with the angle dependency corresponding to a thin single layer of glass without coating [15]. The error is small at normal incidence, but at solar height $45-60^{\circ}$ the error is up to $5 \%$ according to [16] and [17]. If the angle dependency should be considered, it would be necessary to use BSDF data for the glazing. The sun is rarely at normal incidence and therefore it is important to consider non-incident angles of the shading products.

\subsubsection{Modelling integrated and external lamellas}

The integrated blinds and external lamellas were modelled by creating a generic flat lamella geometry at a fixed position, $30^{\circ}$ slat angle, in Rhino. An opaque material was assigned to the slats. Hence, the interreflections between lamellas and glass in the integrated blinds are not considered in DIVA. Both the integrated and external lamellas had two states; retracted and $30^{\circ}$ slat angle.

\subsubsection{Modelling external screen}

The external screen was modelled as a "glass" layer with a perpendicular visual transmission of 0.15 corresponding to the generic fabric chosen in IDA ICE. The screen-fabric is also angle dependent. However, this is disregarded in the thermal simulation, while in DIVA the screen has an angle dependency of a "glass" material. If actual angle dependency should be included, it would be necessary to use BSDF data for the screen for both thermal and daylight simulation. The screen had two states; retracted and closed.

\subsubsection{Modelling MicroShade ${ }^{\circledR}$}

MicroShade ${ }^{\circledR}$ has a highly progressive shading effect that varies with solar height and azimuth angle relative to the product. In order to reflect the angle dependency, 
it was necessary to use a more advanced approach for this shading system.

Since the microstructure in MicroShade $\AA$ is tiny a geometric modelling of the material within a usual daylight simulation is not possible for achieving reliable results. Therefore, a mathematical description of the transmission at varying solar height and azimuth angles was derived and compared to both a geometric model and goniospectrometer measurements of the transmittance. The agreement between the three models can be seen in Fig. 1. [18]

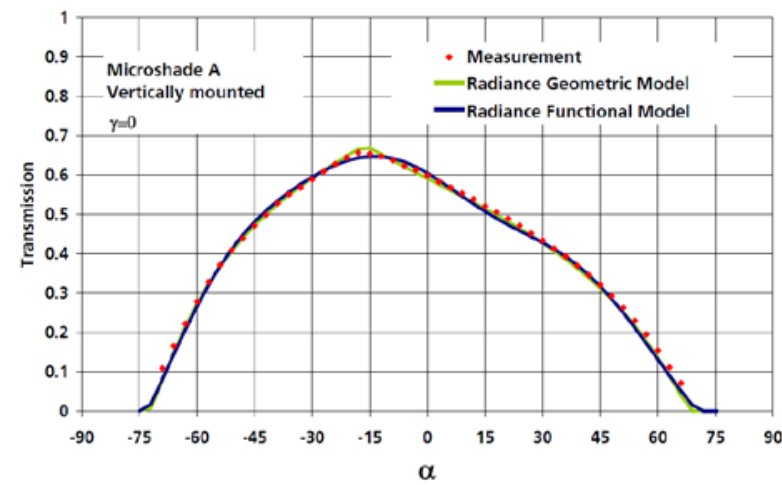

Fig. 1. Angle dependent transmission for the three models of MicroShade ${ }^{\circledR}$ in the solar height direction [18]. $\alpha$ is the solar height and $\gamma$ is the azimuth angle.

The mathematic model uses a Radiance mix function, where air (the holes) and metal (the steel membrane) is mixed. The result is a set of two files; a material description file that calls a .cal file, where the mathematical transmission is calculated. The creation of the files for Radiance was done by Fraunhofer ISE, Germany [18].

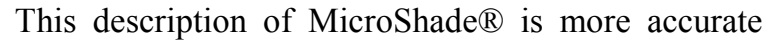
than a BSDF file description as the transmission is calculated continuously, while the BSDF format only has a resolution of $145 \times 145$ Kleems patches.

\section{Workflow}

\subsection{Model Geometry}

The geometry was built up twice; both in Rhino and IDA ICE. Since this model is very simple it was not more time consuming than exporting/importing the model between the software. For larger models, this will most likely not be the case. Having two models in the design process can be very inconvenient since the geometry is often changed during the design. With two set of models accidentally the designers can end up with two different models. There are many different 3D formats and no standardization, which makes it troublesome to export and import between daylight and indoor climate simulation software.

The model in DIVA for Rhino is seen in Fig. 2.

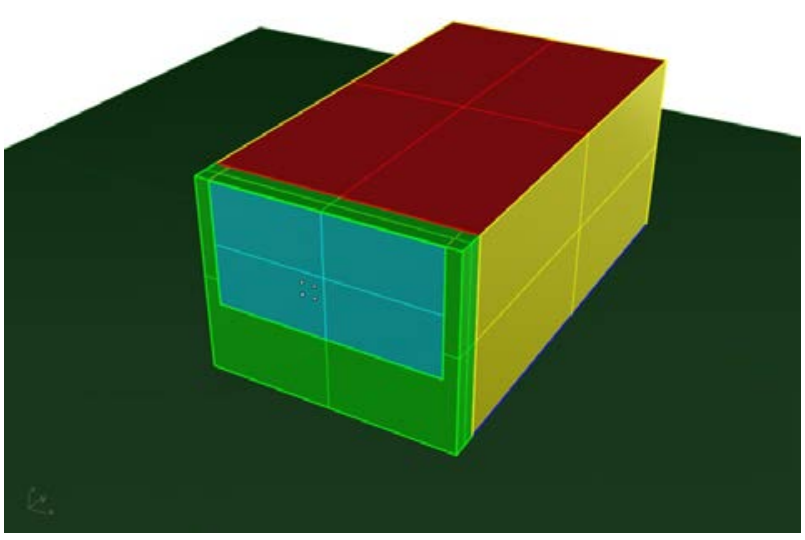

Fig. 2. Building model used for the study. This picture is from Rhino.

\subsection{Weather data}

The weather data used for simulation of daylight and indoor climate also had to be the same. Fortunately, both DIVA for Rhino and IDA ICE use .epw-weather data, so a Meteonorm .epw weather file for Copenhagen was used in the study for both simulations.

\subsection{Control of dynamic shadings}

It was not possible to set up the same definition of control for the dynamic shading systems in DIVA and IDA ICE. An attempt was made to output the control scheme from IDA ICE and use it in DIVA. Since the format of the control scheme was very different in IDA ICE and DIVA the attempt was not successful. An attempt to use the control strategy from DIVA in IDA ICE was also made. This attempt proved to be possible, however, since the control of shading devices are based on achieving acceptable temperatures it turned out that this approach was not useful, as it required too many iterations.

Instead it was chosen to use the shading control scheme from IDA ICE on the hourly daylight results from DIVA in a separate data handling program after all simulations were completed. This was possible because DIVA calculates each state of the shading system for all hours of the year. This also meant that calculation of DGP needed to be left out for the dynamic shadings as this requires the actual control strategy.

The data handling for the dynamic shadings was time consuming and a lot of time could have been saved if it had been possible to import the shading control from IDA ICE into DIVA.

It is our experience that designers often do not align the control strategy of the dynamic shadings between daylight and indoor climate simulations. The process is difficult and time-consuming and often dynamic solar shadings are simply left out of the daylight evaluation. When dynamic shadings are left out the daylight availability is over-estimated, resulting in unsatisfied occupants, who will overmodulate the automatic control to get daylight inside and a view out. It is our experience, that this is one of the reasons why many new high performing buildings do not perform as intended. 


\subsection{CBDM Calculation time and settings}

Calculation time for a yearly calculation of the indoor climate is approximately 1-2 minutes. For CBDM it is between 10 min and 4 hours for the simple model used in this study. The LowE and solar control glazing had a calculation time of app. 10 minutes, while the calculation time for the dynamic shadings and MicroShade ${ }^{\circledR}$ was 3.5-4.5 hours for each scenario. Annual DGP calculations were up to 8 hours.

The simulation time for CBDM depends highly on the simulation settings, however when settings are decreased the accuracy is also decreased. For simple systems such as LowE and solar control glazing low simulation settings are acceptable, however for the more complex systems like the dynamic shadings and MicroShade ${ }^{\circledR}$ it is necessary to use higher simulation setting, which causes the increased simulation time.

The high simulation time is another reason why designers do not include dynamic or complex shading systems in daylight evaluations.

\section{Results}

The six solar shading systems were compared for each orientation to investigate which shading systems had the most optimal performance based on the criteria set up in section 2. However, for conciseness, only results from south and east is shown. In Fig. 3 the indoor climate, daylight and weighted view out is shown for the south orientation.

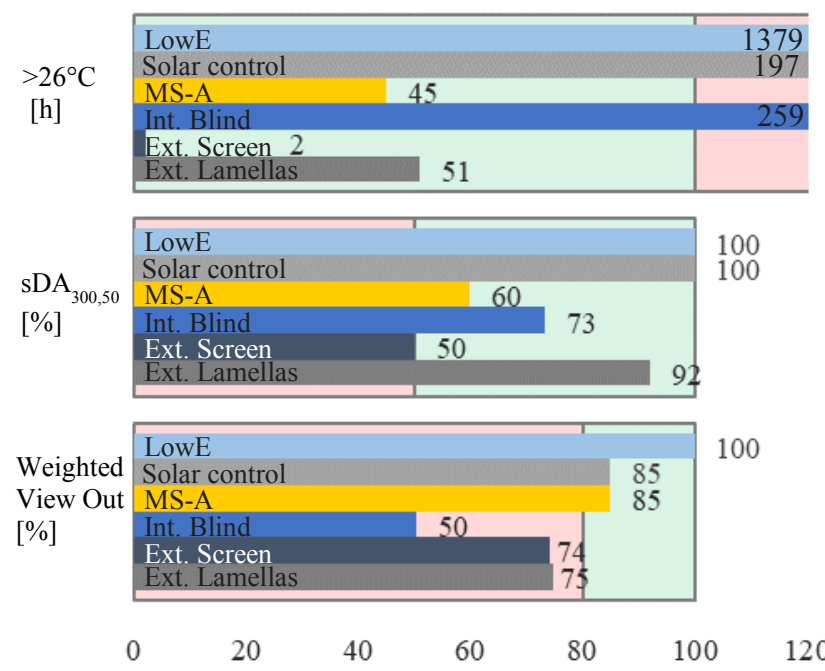

Fig. 3. Indoor climate (EN15251), daylight (EN17037) and weighted view out (EN14501) for the south orientation.

The thermal indoor climate criteria is only meet for

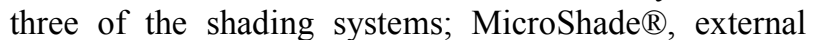
screen and ext. lamellas. All shading systems pass the daylight criteria with the ext. lamellas providing the highest amount of daylight. Only three shading systems passes the weighted view out criteria; LowE, solar control and MicroShade $\AA$. Of the remaining systems external lamellas and screen would pass the weighted view out criteria for "minimum" building class, while the integrated blind would not pass. Overall MicroShade ${ }^{\circledR}$ is the only solution which passes all three criteria.

If the DGP calculation is used as an indicator of how often a supplementary glare protection device is needed and hence blocking the view the results are altered substantially. As described in section 4.2 it was only possible to calculate the DGP for the stationary shading systems as the control scheme from IDA ICE could not be imported into DIVA.

In Table 4 the DGP and weighted view out taking an additional glare device into account is shown.

Table 4. Activation of glare protection and weighted view out incl. glare protection for south facade.

\begin{tabular}{|l|c|c|}
\hline \multirow{2}{*}{$\begin{array}{l}\text { Solar } \\
\text { shading } \\
\text { system }\end{array}$} & $\begin{array}{c}|c| \\
\text { South } \\
\text { activation } \\
\text { of glare } \\
\text { protection } \\
{[\%]}\end{array}$ & $\begin{array}{c}\text { Weighted } \\
\text { view out } \\
\text { incl. glare } \\
\text { protection } \\
{[\%]}\end{array}$ \\
\hline LowE & 40 & 60 \\
\hline Solar control & 28 & 57 \\
\hline MS-A & 15 & 70 \\
\hline Int. blinds & - & - \\
\hline Ext. lamellas & - & - \\
\hline Ext. screen & - & - \\
\hline
\end{tabular}

Only one of the three passive shading system passes the recommendation for view out for a "minimum" class building; that is MicroShade $\AA$, when accounting for glare.

The dynamic shading systems can be controlled in several different ways. Therefore, it was investigated if they could perform better with another control scheme. The integrated blinds were not efficient enough to pass the criteria for indoor climate even when lowering the activation to $50 \mathrm{~W} / \mathrm{m}^{2}$. The external screen and external lamellas were simulated with an activation of $275 \mathrm{~W} / \mathrm{m}^{2}$ and $300 \mathrm{~W} / \mathrm{m}^{2}$ on a south façade. The results are shown in Fig. 4.

The external lamellas pass the indoor climate criteria with a threshold of $250 \mathrm{~W} / \mathrm{m}^{2}$, while for higher thresholds the criteria are not meet. The external screen passes the indoor climate criteria at both $250 \mathrm{~W} / \mathrm{m}^{2}$ and $275 \mathrm{~W} / \mathrm{m}^{2}$. The daylight criteria is passed for all control scenarios, while the weighted view out criteria for a "standard" building is not meet by any of the control schemes. However, the weighted view out criteria for "minimum" building is meet with all control strategies.

The results show, that the performance of dynamic shading systems is highly depended on the control scheme and if automatic control systems does not work as intended it can have a high impact on the indoor environment and energy consumption. It also shows that the view out criteria for "standard" building class cannot be meet by the dynamic shadings. 


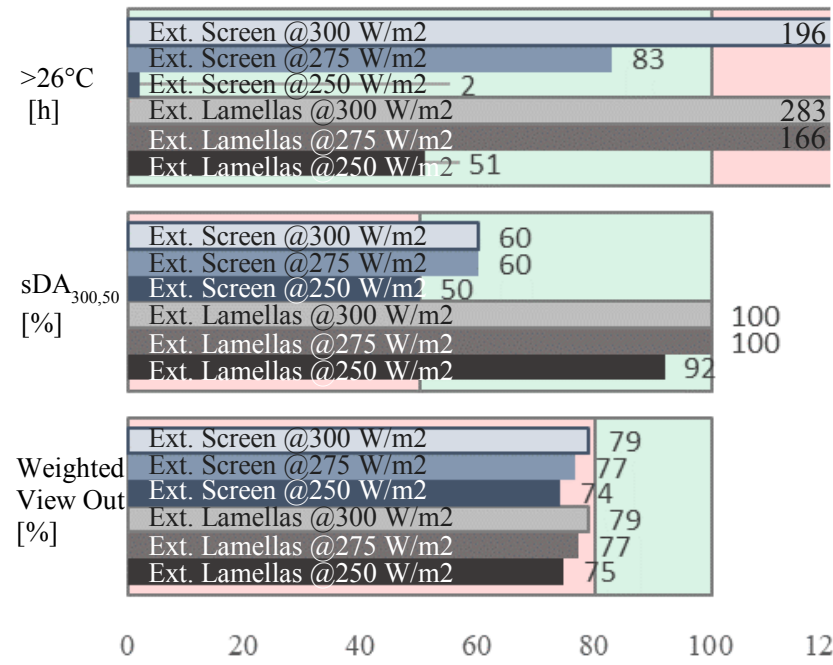

Fig. 4. Indoor climate (EN15251), daylight (EN17037) and weighted view out (EN14501) for varying control of dynamic shadings for south orientation.

In Fig. 5 the indoor climate, daylight and weighted view out is shown for the east orientation.

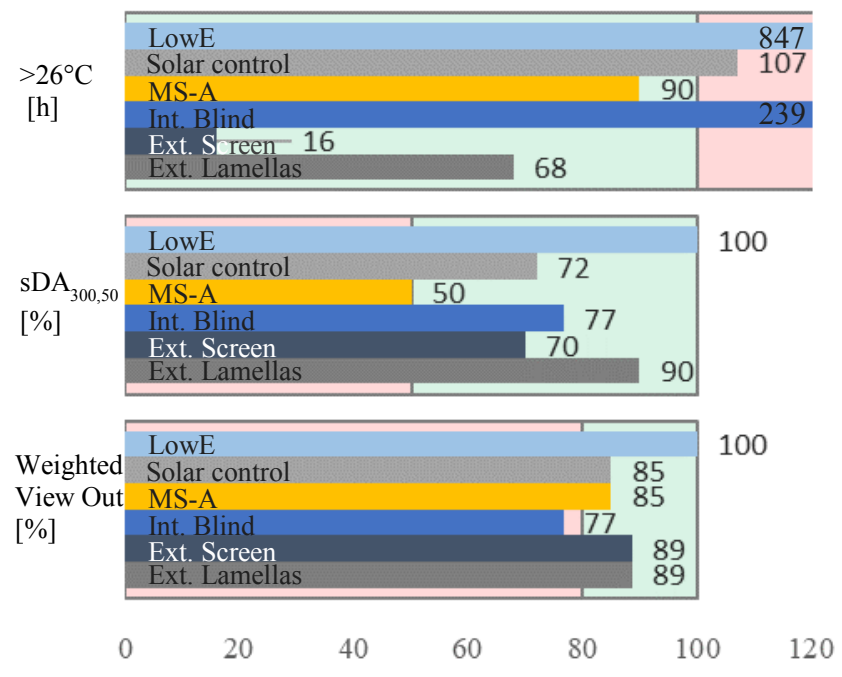

Fig. 5. Indoor climate (EN15251), daylight (EN17037) and weighted view out (EN14501) for the east orientation.

The thermal indoor climate criteria is meet for three solutions; MicroShade $\AA$, external screen and external lamellas. The solar control is very close at meeting the criteria as well. As on the south façade all shading solutions meet the daylight criteria. The weighted view out criteria is meet by all shading solutions except the integrated blinds, which would pass the "minimumclass" building recommendation. It is thus easier to find a suitable solution on the east façade compared to the south façade since both external lamellas, external screen and MicroShade ${ }^{\circledR}$ passes all three criteria.

In Table 5 the DGP and weighted view out taking an additional glare device into account for the east façade is shown.

Only the LowE glazing passes the recommendation for weighted view out for a "standard" class building, while the criteria for a "minimum" class building is meet by the solar control glazing and MicroShade $\AA$.

Table 5. Activation of glare protection and weighted view out incl. glare protection for east facade.

\begin{tabular}{|l|c|c|}
\hline \multirow{2}{*}{$\begin{array}{l}\text { Solar } \\
\text { shading } \\
\text { system }\end{array}$} & $\begin{array}{c}|c| \\
\text { East } \\
\text { activation } \\
\text { of glare } \\
\text { protection } \\
{[\%]}\end{array}$ & $\begin{array}{c}\text { Weighted } \\
\text { view out } \\
\text { incl. glare } \\
\text { protection } \\
{[\%]}\end{array}$ \\
\hline LowE & 16 & 84 \\
\hline Solar control & 13 & 72 \\
\hline MS-A & 11 & 74 \\
\hline Int. blinds & - & - \\
\hline Ext. lamellas & - & - \\
\hline Ext. screen & - & - \\
\hline
\end{tabular}

\section{Conclusion}

The study shows that combining CBDM and indoor climate simulations are difficult. Within the software there are no generic shading systems available, which require every modeler to build their own. Furthermore, the calculation time is long (up to app. 4 hours for an illumination simulation). Both issues are an obstacle for designers to include dynamic or complex shading systems in CBDM.

The control of dynamic shading systems is very different from the control in energy and indoor climate software, which makes it difficult to export/import shading control schemes between programs. This obstacle often results in dynamic shadings being left out of CBDM. Currently, if the control scheme should be shared between CBDM and indoor climate simulations, it requires a manual data handling afterwards in a separate data handling software. With this approach DGP calculations are not possible for dynamic shading systems.

Since the complex interaction between daylight and indoor climate is becoming a key element for designing ZEB buildings, there is a strong need in the marked for software that can link energy, indoor climate and daylight simulations. It is desirable with software where the same 3D building model, same window and shading description, same control strategy for dynamic shadings and same weather data can be used. This will minimize the errors in simulation of buildings.

Furthermore, it would be desirable if the window and shading descriptions could be standardized for both indoor climate and daylight simulation software. Also, weather data and model geometry format standardization would ease the work for designers.

\section{References}

[1] BREEAM International New Construction (2016) Technical Manual SD 2332.0 
[2] LEED v4 for Design and Construction (2018)

[3] EN 17037 Daylight of Buildings (2018)

[4] BR18 Danish Building Regulation (2018)

[5] T.E. Kuhn. State of the art of advanced solar control devices for buildings. Sol. Energy 154 p. 112-133 (2017) [6] J. Christoffersen et al. (1999). Windows and daylight - a field study in office buildings. SBI-report 318.

[7] EN 15251 Indoor environmental input parameters for design and assessment of energy performance of buildings-addressing indoor air quality, thermal environment, lighting and acoustics. (2007)

[8] EN 14501 Blinds and shutters - Thermal and Visual Comfort-Performance characteristics and classification. (2005)

[9] M. Vorre et al. Industry-guideline for indoor climate simulations (2017), SBI

[10] https://www.radiance-online.org/

[11] T.S. Pedersen et al. Workflow for coupled daylight and energy simulations. Clima2019 procedings. (2019)

[12] http://diva4rhino.com/

[13] https://www.equa.se/en/

[14] ISO 15099. Thermal performance of windows, doors and shading devices -- Detailed calculations.

(2003)

[15] http://radsite.lbl.gov/radiance/refer/materials.pdf

[16] https://unmethours.com/question/1037/convertingtransmittance-to-transmissivity-for-igus/

[17] M. Rubin et al. Model for angle-dependent optical properties of coated glazing materials. Sol. Energy 66 p. 267-276. (1999)

[18] J. Wienold. Thermal and optical characterization of MicroShade ${ }^{\circledR}$ Daylighting and Glare evaluation. Report TAG3-JW-1201-E01 (2012) 